\title{
Information needs and oral epithelial dysplasia: development and psychometric evaluation of a novel instrument
}

Abdullah Alsoghier ${ }^{a, b^{*}}$, Richeal Ni Riordain ${ }^{\mathbf{a}, \mathbf{c}}$, Stefano Fedele ${ }^{\mathbf{a}, \mathbf{d}}$, Colin Liew ${ }^{\mathrm{e}}$, Stephen Portera

a UCL Eastman Dental Institute, University College London, London, UK

${ }^{b}$ College of Dentistry, King Saud University, Riyadh, Saudi Arabia

${ }^{c}$ Cork University Dental School and Hospital, University College Cork, Ireland

d NIHR University College London Hospitals, Biomedical Research Centre, London, UK

e University College London Hospitals, Head and Neck Centre, London, UK

*Corresponding author: UCL Eastman Dental Institute, 256 Gray's Inn Road, London, WC1X 8LD, Tel: $+44 \quad(0) 203456$ 1038, Fax: $+44 \quad(0) 203456$ 1039, E-mail: a.alsoghier@ucl.ac.uk

Keywords: Health Education; Information needs; Needs Assessment; Patient Preference; Validation Study; Precancerous Conditions.

Date of submission: $11^{\text {th }}$ of November 2020

Conflict of Interest: None

\begin{abstract}
Objectives

Oral epithelial dysplasia (OED) can lead to significant information needs (IN) related to the risk of cancer development, the need for long-term monitoring and potential

This article has been accepted for publication and undergone full peer review but has not been through the copyediting, typesetting, pagination and proofreading process, which may lead to differences between this version and the Version of Record. Please cite this article as doi: $\underline{10.1111 / O D I .13726}$
\end{abstract}

This article is protected by copyright. All rights reserved 
intervention. The present study aimed to develop and perform preliminary psychometric testing for a novel IN instrument specific to OED.

\section{Subjects and methods}

Patients diagnosed with OED were invited to complete the Oral Epithelial Dysplasia Informational Needs Questionnaire (ODIN-Q), which was developed based on a known theoretical framework and with items generated via expert input and the literature. Face and content validity were initially assessed prior to finalisation of the tool. ODIN-Q was tested for internal consistency and test-retest reliability along with construct validity.

\section{Results}

ODIN-Q consists of 35 items, categorised under six domains, and rated by dual four-point Likert scales (amount of information received and degree of importance). Internal consistency (Cronbach's alpha) was rated 'excellent' for the scale (0.93) and both subscales (0.92/0.94). For test-retest reliability, moderate agreement was found $(\mathrm{K}=$ 0.49-0.53). Regarding construct validity, a significant but limited relationship was found between ODIN-Q and the Krantz Health Opinion Survey.

\section{Conclusion}

ODIN-Q showed adequate psychometric properties of reliability and validity. Further validation is, however, needed to assess its structural validity and responsiveness. 


\section{Introduction}

Oral epithelial dysplasia (OED) is an architectural and cytological abnormality of the oral epithelium characterised by an increased risk of oral cancer development (Mehanna, Rattay, Smith, \& McConkey, 2009). It is considered a precursor of invasive oral squamous cell carcinoma, which is known to arise via sequential genetic and cytologic changes (Cho \& Song, 2018). Oral epithelial dysplasia is diagnosed histologically, often in association with clinically evident abnormality of the oral mucosa including leukoplakia, erythroplakia, and oral lichen planus. Available literature suggests that approximately $12 \%$ of OED patients develop oral squamous cell carcinoma within a mean of 4.3 years from diagnosis, although the sub-group of individuals with severe OED is reported to develop oral cancer in up to $24 \%$ of the cases (Mehanna et al., 2009). A recent systematic review report an annual rate of oral cancer development of $1.7 \%$ and $3.5 \%$ for mild and severe OED, respectively (locca et al., 2020). Well-established risk factors include tobacco use, alcohol drinking and betel nut chewing (locca et al., 2020). In contrast, the pathogenetic role of other factors such as high-risk HPV types (e.g. HPV-16 and 18) is yet to be conclusively demonstrated in OED (Porter, Gueiros, Leao, \& Fedele, 2018). Management of OED typically includes long-term surveillance, which can be lifelong (van der Waal, 2014) as well as surgery, although there remains little robust evidence regarding the efficacy of surgical resection in reducing the risk of oral cancer development (Mehanna et al., 2009).

Due to potential very long monitoring, the information provided to patient becomes a pivotal aspect of OED management. Previous research has suggested that insufficient information on health conditions can induce the fear of the unknown and uncertainty (Carleton, 2016) and, with respect to OED, this may be perceived as a barrier to seek oral cancer screening (Shepperd, Howell, \& Logan, 2014). In contrast, information may in some instances lead to a cognitive overload for the patients, who may forget relevant information. Not all patients wish for all information (Christalle et al., 2019), which can be perceived as too alarmist and distressing, and cause anxiety (Waldron et al., 2011).

In general, appropriately informed patients experience reduced uncertainty than less informed patients that can, in turn, improve their compliance and satisfaction with treatment, ability to cope with the illness or adverse side effects of therapy and overall perception of the quality of care (Clarke et al., 2015; Neumann et al., 2011). Despite the 
pervasive use of the Internet, health care professionals (HCPs) remain the most reliable source of health-related information. The information available on the world wide web may be of poor quality, difficult to read or comprehend and lack actionability (Alsoghier, Ni Riordain, Fedele, \& Porter, 2018). Nevertheless, there is often a gap between information needed by patients and that provided by their clinicians, and hence a risk of poor shared decision-making between the patient and HCPs (Rask, 2017; Weymann, Harter, \& Dirmaier, 2016). Closing such a gap requires the delivery of tailored information based up on a patient's true needs and preferences (National Institute for Clinical Excellence, 2012; Neumann et al., 2011). One increasingly common method to do so is to acquire this information by using patient-reported experience measures (PREMs) such as information needs (IN) instruments (Christalle et al., 2019; Dall'Armi et al., 2013). Information needs instruments can be useful to identify the individual's IN and therefore may serve as an educational source for tailored and relevant information (Christalle et al., 2019). Numerous IN generic and specific instruments available for different conditions with many of these instruments lacking reliability assessment and hypothesis testing and being rated as inadequate for content validity (Christalle et al., 2019). Of importance, none of these measures is known to accurately assess the sufficiency and importance of information given about OED. Information needs were previously evaluated in the context of oral precancerous lesions (Lin, Chen, Peng, \& Chen, 2015) and oral cancer (Chen, Lai, Liao, Chang, \& Lin, 2009). However, available studies used non-specific IN instruments (e.g. a cancer-generic instrument for oral cancer and precancerous conditions), therefore raising possible concern regarding their validity in this diseasespecific group. The objectives of the present study are to develop the Oral Epithelial Dysplasia Informational Needs Questionnaire (ODIN-Q) and preliminary assess its psychometric properties - content and face validity, construct validity (hypothesis testing), test-retest reliability and internal consistency in a cohort of patients diagnosed with OED at a single UK site.

\section{Methods}

This was a prospective, observational questionnaire-based quantitative study conducted from October 2017 to December 2019. Ethical approvals were obtained from the Cork University Dental Hospital in Ireland [dated 26 October 2017] and the NHS Health 
Research Authority, Research Ethics Committees [reference, 18/LO/1340] for the pilot and validation studies, respectively. The study was registered in https://clinicaltrials.gov [reference, NCT04153266]. Inclusion and exclusion criteria are presented in Table 1.

\section{Development of ODIN-Q}

The stress and coping theory (Lazarus \& Folkman, 1984) guided the development of ODIN-Q. It suggests that dealing with stressful events [e.g. receiving a diagnosis with oral precancer] requires multiple behavioural and cognitive strategies to be adopted by individuals, including seeking information to understand the new health-related and possibly alarming event and its effect on well-being (Galloway et al., 1997; Lazarus \& Folkman, 1984). This theory was considered suitable as a theoretical foundation for IN tools in patients with various health conditions (Galloway et al., 1997; Rask, 2017). The items for ODIN-Q were adapted and modified from the following IN instruments, as well as literature and clinicians' input (Pian, Song, \& Zhang, 2019):

1) Reliable, valid and highly adopted IN instruments for patients with metastatic disease (Cassileth, Zupkis, Sutton-Smith, \& March, 1980), breast cancer (Galloway et al., 1997; Luker et al., 1995) and prostate cancer (Dale, Jatsch, Hughes, Pearce, \& Meystre, 2004).

2) The concerns reported in quantitative and qualitative studies of oral potentially malignant disorders (OPMDs) (Lin et al., 2015; Tadakamadla, Kumar, Lalloo, \& Johnson, 2017), oral cancer or its symptoms (Allen \& Farah, 2015) as well as non-oral cancer (Tariman, Doorenbos, Schepp, Singhal, \& Berry, 2014) and precancerous conditions (Rask, 2017).

3) Input from Oral Medicine clinicians (RNR and SP) based on the expert opinion, available evidence and common concerns reported by patients in the daily clinical practice.

When considering the scale properties for ODIN-Q, the dual scale format adapted from Dale's IN instrument for prostate cancer (Dale et al., 2004) was considered appropriate as it assesses how sufficient was the information on an item (too much, enough, not enough, none) and whether it is important (very, yes, not very, not at all). The initial version included 56 questions which were not labelled under domains (Galloway et al., 1997 ) as agreed initially by the study team. 
Qualitative assessment of ODIN-Q (content and face validity)

Expert review of ODIN-Q

The initial version of ODIN-Q ( $\vee 1.0)$ was reviewed by thirteen Oral Medicine experts to confirm its content validity. A checklist of four specific criteria [clarity, statement fit, redundancy and consistency] was followed to assess the content of ODIN-Q (Mastaglia, Toye, \& Kristjanson, 2003). The majority of experts (84\%) considered the items to be matching and asking about the same general topic. Nevertheless, around half of the experts noted some concerns regarding the clarity and redundancy of specific items, which indicated the need for further revisions (Figure 1). Examples of the received feedback from experts and performed actions are shown in Table 2. Experts have also recommended grouping the items under domains to maintain the reliability of responses and excluding unclear, irrelevant and redundant items which led to a reduction of items from 56 to 37.

Patient review of ODIN-Q

Face validity, which is an aspect of content validity, was determined by a sample of 5 patients attending Oral Medicine Clinics at Cork University Dental Hospital in Ireland. This sample included 3 males and 2 females patients with a mean age of 60 years (38-73 years).

At the time when the study was planned, there was no available method to assess or quantify the face validity (October 2017-April 2018). A Delphi study that provided standardised methods to assess the content and face validity was however published later to the assessment (Terwee et al., 2018). Thus, an evaluation form similar to that used for experts (Mastaglia et al., 2003) was modified to include questions concerning clarity [is the questionnaire clear?], relevance [is the questionnaire related to your condition?] and acceptability [in general, do you find the questionnaire acceptable?] (Moses, Wiggers, Nicholas, \& Cockburn, 2005) rather than statement fit, redundancy and consistency. The participants requested to change questions with medical jargon, reword and shorten specific questions and omitting two questions related to insurance and spiritual/religious support (Table 2). Further revisions improved the readability from the $6^{\text {th }}$ grade level (Kincaid, Fishburne Jr, Rogers, \& Chissom, 1975) in the initial version to the 
level between $4^{\text {th }}$ and $5^{\text {th }}$ grades in the later version of ODIN-Q ( $v$ 2.0). Both were measured by an online readability calculator (https://readable.com).

\section{Validation study of ODIN-Q}

The study investigator (AA) identified the potential participants among the patients attending their regular clinics and invited them to consider participation. Those who meet all the inclusion and none of the exclusion criteria were recruited and asked to complete the self-administered study questionnaires after their routine clinical visit or at home and return it by post. To determine the scale repeatability participants were asked to complete the ODIN-Q one week after their initial attempt and return the completed ones using the given pre-paid envelopes.

There are no standardised statistical methodological tests available to assess and validate an IN questionnaire. However, the recently developed checklists by the COnsensus-based Standards for the selection of health Measurement Instruments (COSMIN) to determine the psychometric properties of PROMs were followed for ODIN$Q$ validation (Mokkink et al., 2019; Prinsen et al., 2018).

Internal consistency was measured through Cronbach's $\alpha$, which was interpreted as excellent $(>.90)$, good $(>0.80)$, acceptable $(>0.70)$, questionable $(>0.60)$, poor $(>0.50)$ and unacceptable (<0.50) (George \& Mallery, 2003).

As participants were asked to complete the ODIN-Q again one week after their initial attempt, the consistency of both completions (test-retest reliability) was assessed using the weighted Cohen's kappa coefficient ( $\mathrm{K}$ ) for ordinal scales (Sim \& Wright, 2005). Although the interpretation for $\mathrm{K}$ coefficients is commonly arbitrary, these were interpreted as almost perfect $(0.81$ or higher) substantial $(0.80-0.61)$, moderate $(0.60-0.41)$ and fair if at or below 0.40 (Landis \& Koch, 1977).

Construct validity or hypothesis testing was assessed by comparisons between ODIN-Q and another instrument that measures a similar construct [convergent validity] (Mokkink et al., 2019). The sum scores of ODIN-Q subscales were matched to those of the Krantz Health Opinion Survey (KHOS) (Krantz, Baum, \& Wideman, 1980). KHOS is one of the 
highly used and reliable instruments that has been used to assess the preference for information (KHOS-I, seven items) and active involvement in own health care decisions (KHOS-B, nine items). Shapiro-Wilk normality test indicated the skewed distribution of ODIN-Q scores $(P<.05)$. Thus, the Spearman's rank correlation coefficient with a twotailed test of significance was used to measure the magnitude of correlations between the scores of ODIN-Q and KHOS (Dinning \& Crampton, 1989).

For sample size calculation, there is no present consensus to determine the sample size for the validation of a patient outcome measure (Anthoine, Moret, Regnault, Sébille, \& Hardouin, 2014). However, the COSMIN checklist for study design of PROMs suggests that sample size, based on general guidance (Prinsen et al., 2018), can be excellent ( $\geq 100$ participants), good (99-50), fair (49-30), or poor (<30).

Data analysis and quality control

Responses to ODIN-Q were recorded using Microsoft Excel proforma (version 16.29.1) and imported to the IBM Statistical Package for Social Sciences (SPSS) software (version 22.0) for statistical analyses. Questionnaires with non-responses of $\geq \% 10$ for each subscale of ODIN-Q were omitted whereas those of less were matched to the average answer of each item (Downey \& King, 1998).

\section{Results}

Following the assessments by experts and patients, the revised version of ODIN-Q ( $\mathrm{v}$ 3.0) included 35 questions about IN that was represented under six domains (general information, investigative tests, treatments, physical aspects, psychosocial aspects and the medical system and access to information). Other questions on the preferred sources of information, ranking of HCPs - if one-to-one is selected and the open-ended question at the end of ODIN-Q were maintained for this version. Steps performed from identifying the potentially eligible patients to recruitment are highlighted in Figure 2.

The 86 participants were 41 males and 45 females. $78 \%$ of them were White and the remaining $22 \%$ of Asians, Black or mixed ethnicity. The mean and median age was at 65 
years (31-89 years). Based on WHO grading for OED (El-Naggar, Chan, Grandis, Takata, \& Slootweg, 2017), 63\% of participants had the diagnosis of mild and mild to moderate grades, $19 \%$ of moderate and $18 \%$ of moderate to severe and severe dysplasia.

\section{Psychometric properties of ODIN-Q}

Reliability

\section{Internal consistency}

The estimates of correlations between all items of ODIN-Q by Cronbach's $\alpha$ showed excellent internal consistency for items under the amount of information received ( $\alpha=$ $0.92)$ and degree of importance subscales $(\alpha=0.94)$ and for the overall scale of ODIN-Q ( $\alpha=0.93$ ). The analyses of domains under each subscale demonstrated that most domains had good $(>80)$ or acceptable consistency $(>.70)$. Exceptions were seen with investigative tests and psychosocial aspects domains under both subscales, which showed questionable (>.60) to poor consistency (>.50). However, both domains showed higher scores when one item was removed from the analyses of former and latter domains, respectively (Table 3). Also, the Spearman's test indicated no statistically significance $[p>.05]$ and/or low inter-item correlations $[r<0.40]$ (Guilford, 1950) between these two items and other items under the first subscale.

\section{Test-retest reliability}

The analyses of agreement between the first and second completions by 52 out of the 86 participants, who returned the 2nd-week questionnaires by mail, indicated moderate agreements for both subscales: the amount of information received $(\kappa=0.53)$ and the degree of importance $(\mathrm{k}=0.49)$. Similarly, the agreements on all domains under both subscales were rated as moderate; information about the disease (0.50 and 0.49), investigative tests $(0.45$ and 0.41$)$, treatments $(0.55$ and 0.52$)$, physical aspects $(0.53$ and 0.48$)$, psychosocial aspects $(0.61$ and 0.43$)$ and medical system and access to 
information (0.55 and 0.53 ). Values of most items indicated substantial to moderate agreements with few others, however, demonstrated fair agreements (Table 4).

\section{Validity}

Construct validity (Hypothesis testing)

After excluding the multiple missing responses for KHOS-I and KHOS-B $(n=4)$, the responses of 82 participants for both subscales against ODIN-Q subscales showed a statistically significant positive linear relationship between the preference for information (KHOS-I) and amount of information received subscale of ODIN-Q $(r=.232, p<.05)$. This degree of correlation is considered definite but limited (Guilford, 1950). In contrast, higher levels of correlation were found when KHOS subscales and scale when compared to each other (Table 5).

The final version of ODIN-Q after the validation study

Two items ['the genetic testing and chance of inheritance to children' and 'how the disease/treatment affects the job/career] were omitted from the final version based on the reliability analyses and relevance to the clinical care of patients with OED. The characteristics and content of the 33-item ODIN-Q ( 13.0$)$ are shown in Supplementary file 1.

\section{Discussion}

A substantial body of literature has highlighted the importance of patient education and the provision of information in shared-decision making and management of chronic and premalignant disease (Grilo, dos Santos, Gomes, \& Rita, 2017; Lin et al., 2015), such as perhaps OED. Also, providing reliable information to dental patients could optimise the awareness of their disease (Ali, Woodmason, \& Patel, 2014) and improve the early detection of new OED lesions or possibly the malignant transformation of existing lesions. This is illustrated by the locus of control (LOC) theory (Rotter, 1966) which is constituted 
by two loci. The internal LOC reflects the individual belief in self-control over his/her health. In contrast, external LOC demonstrates the belief in health control or influence by factors that cannot be controlled by the individual (Rotter, 1966; Syx, 2008). Of note, higher control over health outcomes is likely to be found among those who have their beliefs driven by the internal LOC when communicated with health information (Krantz et al., 1980; Syx, 2008).

The development and validation of the present ODIN-Q was performed by teaming up patients and clinical experts to maintain essential aspects of methodological quality that ensure adequate reliability and validity to identify the needs and priorities of patient information about OED. Similar to two studies on the breast (Chalmers, Luker, Leinster, Ellis, \& Booth, 2001) and prostate cancer (Dale et al., 2004), the dual-scale ODIN-Q has the advantages of measuring whether information received on a topic was sufficiently met and whether this topic is essential to the respondent despite their answer in the first subscale. Other instruments were limited for assessing either of these subscales, such as degree of importance (Dall'Armi et al., 2013; Galloway et al., 1997) or presented different responses for each item (Hyland, Jones, \& Hanney, 2006).

The present ODIN-Q demonstrated adequate validity with its overall content been reviewed and revised by experts who mainly agreed on its relevance and acceptability. To improve the efficiency of the ODIN-Q, resolving concerns related to its clarity and redundancy led to a reduction in the number of items from 56 to 37 and 35 and 33 items following the experts and patients reviews and the validation study, respectively. Similar to these findings, the assessments of content and face validity of other patient's needs instruments helped to eliminate unnecessary items concerning prostate cancer (Dale et al., 2004) and to change the format of specific others related to the cancer needs of young individuals (Clinton-McHarg, Carey, Sanson-Fisher, D'Este, \& Shakeshaft, 2012). Although instruments must be readable by the targeted population especially individuals with less education (Bonevski et al., 2000; Clinton-McHarg et al., 2012), assessing the readability levels of IN tools is frequently overlooked. ODIN-Q maintained the recommended readability level of $4^{\text {th }}$ to $5^{\text {th }}$ US grade level, which was slightly lower than the initially reported level of generic cancer needs instrument $\left[6^{\text {th }}\right.$ grade level] (ClintonMcHarg et al., 2012). 
Another aspect of validity, hypotheses testing, was determined by assessing the relationship of ODIN-Q with an instrument with adequate psychometric properties and measuring similar construct (desire for information) (de Vet, Terwee, Mokkink, \& Knol, 2011; Mokkink et al., 2019). Within the limitation of the relationship, the present findings indicated that respondents who had their IN sufficiently met were those who have a higher preference for information. These findings are perhaps explained by the commonly adopted and ODIN-Q-based hypothesis of stress, appraisal and coping theory (Lazarus \& Folkman, 1984) in health information-seeking behaviour research - that consider the desire for information and behavioural involvement as two of the strategies to maintain the control and coping to a stressful health condition (Rutten, Arora, Bakos, Aziz, \& Rowland, 2005; White \& Gallagher, 2010). As a consequence, these participants will have sufficient information and met IN compared with their passive counterparts, as reported with a study that investigated these behaviours using KHOS in 260 patients undergoing oral biopsy in Spain (Lopez-Jornet, Camacho-Alonso, \& Sanchez-Siles, 2012).

Overall, the ODIN-Q has been found to be reliable by achieving excellent internal consistency (Cronbach's $\alpha$ ) of 0.91 with an adequate sample size of 86 participants. This is comparable to the instruments that were mainly used to develop ODIN-Q: TINQ-BC (0.96) and Dale's IN instrument for prostate cancer (0.91) (Dale et al., 2004; Galloway et al., 1997). Assessments of test-retest reliability using weighted $\mathrm{k}$ demonstrated overall moderate agreements for both ODIN-Q subscales with less variation of scores between items ( $\mathrm{K}=0.20-0.76$ ) compared to the Cancer Needs Questionnaire $(\mathrm{K}=0.09-0.94)$ (Clinton-McHarg et al., 2012), and somewhat similar to the unweighted $\mathrm{k}$ values reported with the Systemic Lupus Erythematosus Needs Questionnaire ( $k=0.32-0.70$ ) (Moses et al., 2005). Comparisons with similar IN instruments are not possible due to different methods to measure agreements including intraclass correlation coefficients (Ghisi, Grace, Thomas, Evans, \& Oh, 2013) or lack of evidence on test-retest reliability (Alamanou, Balokas, Fotos, Patiraki, \& Brokalaki, 2016; Dale et al., 2004).

The present study was limited by the lack of assessments of fundamental psychometric properties such as criterion validity (Mokkink et al., 2019). Furthermore, responsiveness was not presently assessed as the study did not principally aim to detect the overtime changes of IN. Although a sample of 86 participants is considered adequate to evaluate 
the internal consistency (Mokkink et al., 2019), further validation is needed to demonstrate acceptable level for consistency $(>0.70)$ for investigative tests and psychosocial aspects domains which were initially below this level. Also, a minimum of five respondents for each item is recommended for the factor analysis (Comrey, 1992). As the ODIN-Q was developed based on a sound theoretical framework that has been used in other information needs questionnaire, the exploratory factor analysis was not necessary.

Due to the relatively low incidence rate of OED, further research may consider multicentre recruitment to uphold an adequate sample needed to perform the confirmatory factor analysis (structural validity) and field-testing of ODIN-Q, which will provide further evidence on its reflection of the patient's IN (de Vet et al., 2011; Nankivell, Dunn, Langman, \& Mehanna, 2012; Prinsen et al., 2018). Cross-cultural validation will also be needed for its application in patients with a specific disease (e.g. patients diagnosed with oral lichen planus), ethnicity (e.g. minority groups), age-group (e.g. young individuals), health care setting (e.g. primary care) in addition to other languages and countries. Furthermore, longitudinal IN assessments using ODIN-Q would enable to evaluate the changes of IN overtime as well as before and after implementing educational interventions (responsiveness) (de Vet et al., 2011).

\section{Conclusion}

A questionnaire was developed to determine what information is needed and how important it is for patients with OED. The assessment of the psychometric properties of this questionnaire (ODIN-Q) with 86 patients demonstrated its excellent internal consistency and moderate agreements between first- and second-week completions. Also, the construct validity was reflected with a significant but limited relationship between ODIN-Q and another instrument of similar construct. Further longitudinal and perhaps a cross-cultural assessment of ODIN-Q is however needed with an adequate cohort of patients with OED to determine its structural validity and responsiveness to confirm its accurate reflection of the respondent's information needs. 


\section{Acknowledgements}

We thank the study participants and clinicians who actively participated in the development and validation of the ODIN-Q. Also, thanks to the Eastman Clinical Investigation Centre (ECIC) at UCL Eastman Dental Institute for the support and clinical governance of the present study. This study did not receive any specific research grant from funding agencies in public, commercial or not-for-profit sectors. Service support funding were provided by the NIHR Clinical Research Network. AA held PhD studies grant from King Saud University, Saudi Arabia. RNR received funding from the NIHR UCLH/UCL Biomedical Research Centre (BRC).

\section{References}

Alamanou, G. D., Balokas, A. S., Fotos, V. N., Patiraki, E., \& Brokalaki, H. (2016). Information needs of cancer patients: Validation of the Greek Cassileth's Information Styles Questionnaire. Eur J Oncol Nurs, 20, 49-57. doi:10.1016/j.ejon.2015.11.002

Ali, S., Woodmason, K., \& Patel, N. (2014). The quality of online information regarding dental implants. Br Dent J, 217(9), E16. doi:10.1038/sj.bdj.2014.979

Allen, K., \& Farah, C. S. (2015). Patient perspectives of diagnostic delay for suspicious oral mucosal lesions. Aust Dent J, 60(3), 397-403. doi:10.1111/adj.12246

Alsoghier, A., Ni Riordain, R., Fedele, S., \& Porter, S. (2018). Web-based information on oral dysplasia and precancer of the mouth - Quality and readability. Oral Oncol, 82, 69-74. doi:10.1016/j.oraloncology.2018.05.003

Anthoine, E., Moret, L., Regnault, A., Sébille, V., \& Hardouin, J.-B. (2014). Sample size used to validate a scale: a review of publications on newly-developed patient reported outcomes measures. Health Qual Life Outcomes, 12, 2. doi:10.1186/s12955-014-0176-2 
Bonevski, B., Sanson-Fisher, R., Girgis, A., Burton, L., Cook, P., \& Boyes, A. (2000). Evaluation of an instrument to assess the needs of patients with cancer. Supportive Care Review Group. Cancer, 88(1), 217-225. doi:10.1002/(SICl)10970142(20000101)88:1<217::AID-CNCR29>3.0.CO;2-Y

Carleton, R. N. (2016). Into the unknown: A review and synthesis of contemporary models involving uncertainty. J Anxiety Disord, 39, 30-43. doi:10.1016/j.janxdis.2016.02.007

Cassileth, B. R., Zupkis, R. V., Sutton-Smith, K., \& March, V. (1980). Information and Participation Preferences Among Cancer Patients. Ann Intern Med, 92(6), 832-836. doi:10.7326/0003-4819-92-6-832

Chalmers, K. I., Luker, K. A., Leinster, S. J., Ellis, I., \& Booth, K. (2001). Information and support needs of women with primary relatives with breast cancer: development of the Information and Support Needs Questionnaire. J Adv Nurs, 35(4), 497-507. doi:10.1046/j.1365-2648.2001.01866.x

Chen, S. C., Lai, Y. H., Liao, C. T., Chang, J. T., \& Lin, C. C. (2009). Unmet information needs and preferences in newly diagnosed and surgically treated oral cavity cancer patients. Oral Oncol, 45(11), 946-952.

doi:10.1016/j.oraloncology.2009.06.002

Cho, K.-J., \& Song, J. S. (2018). Recent changes of classification for squamous intraepithelial lesions of the head and neck. Arch Pathol Lab Med, 142(7), 829-832. doi:10.5858/arpa.2017-0438-RA

Christalle, E., Zill, J. M., Frerichs, W., Harter, M., Nestoriuc, Y., Dirmaier, J., \& Scholl, I. (2019). Assessment of patient information needs: A systematic review of measures. PLoS One, 14(1), e0209165. doi:10.1371/journal.pone.0209165

Clarke, M. A., Moore, J. L., Steege, L. M., Koopman, R. J., Belden, J. L., Canfield, S. M., . . Kim, M. S. (2015). Health information needs, sources, and barriers of primary care patients to achieve patient-centered care: A literature review. Health Informatics J, 22(4), 992-1016. doi:10.1177/1460458215602939

Clinton-McHarg, T., Carey, M., Sanson-Fisher, R., D'Este, C., \& Shakeshaft, A. (2012). Preliminary development and psychometric evaluation of an unmet needs measure for adolescents and young adults with cancer: the Cancer Needs 
Questionnaire - Young People (CNQ-YP). Health Qual Life Outcomes, 10, 13. doi:10.1186/1477-7525-10-13

Comrey, A. L. (1992). A first course in factor analysis / by Andrew L. Comrey and Howard B. Lee (2nd ed.). Hillsdale, N.J: L. Erlbaum Associates.

Dale, J., Jatsch, W., Hughes, N., Pearce, A., \& Meystre, C. (2004). Information needs and prostate cancer: the development of a systematic means of identification. BJU Int, 94(1), 63-69. doi:10.1111/j.1464-410X.2004.04902.x

Dall'Armi, L., Simpson, G. K., Forstner, D., Simpson, T., Roydhouse, J. K., \& White, K. J. (2013). The information needs of patients with head and neck cancer and their caregivers: a short report of instrument development and testing. Appl Nurs Res, 26(1), 40-44. doi:10.1016/j.apnr.2012.08.001

de Vet, H. C. W., Terwee, C. B., Mokkink, L. B., \& Knol, D. L. (2011). Measurement in Medicine: A Practical Guide. Cambridge: Cambridge University Press.

Dinning, W. D., \& Crampton, J. (1989). The Krantz Health Opinion Survey: correlations with preventive health behaviors and intentions. Psychol Rep, 64(1), 59-64. doi:10.2466/pr0.1989.64.1.59

Downey, R. G., \& King, C. V. (1998). Missing data in Likert ratings: A comparison of replacement methods. J Gen Psychol, 125(2), 175-191. doi:10.1080/00221309809595542

El-Naggar, A. K., Chan, J. K. C., Grandis, J. R., Takata, T., \& Slootweg, P. J. (2017). WHO classification of head and neck tumours. In (4th ed., Vol. 9). Lyon, France: International Agency for Research on Cancer (IARC).

Galloway, S., Graydon, J., Harrison, D., Evans-Boyden, B., Palmer-Wickham, S., BurleinHall, S., . . Blair, A. (1997). Informational needs of women with a recent diagnosis of breast cancer: development and initial testing of a tool. $J$ Adv Nurs, 25(6), 11751183. doi:10.1046/j.1365-2648.1997.19970251175.x

George, D., \& Mallery, P. (2003). SPSS for windows step by step : a simple guide and reference (11.0 update) (4th ed. ed.). Boston, MA: Allyn \& Bacon.

Ghisi, G. L., Grace, S. L., Thomas, S., Evans, M. F., \& Oh, P. (2013). Development and psychometric validation of a scale to assess information needs in cardiac rehabilitation: the INCR Tool. Patient Educ Couns, 91(3), 337-343. doi:10.1016/j.pec.2013.01.007 
Grilo, A. M., dos Santos, M. C., Gomes, A. I., \& Rita, J. S. (2017). Patient Centered Medicine (1st ed.). Rijeka, Croatia: In Tech.

Guilford, J. P. (1950). Fundamental statistics in psychology and education (2nd ed.). New York: McGraw-Hill.

Hyland, M. E., Jones, R. C., \& Hanney, K. E. (2006). The Lung Information Needs Questionnaire: Development, preliminary validation and findings. Respir Med, 100(10), 1807-1816. doi:10.1016/j.rmed.2006.01.018

locca, O., Sollecito, T. P., Alawi, F., Weinstein, G. S., Newman, J. G., De Virgilio, A., . . Shanti, R. M. (2020). Potentially malignant disorders of the oral cavity and oral dysplasia: A systematic review and meta - analysis of malignant transformation rate by subtype. Head Neck, 42(3), 539-555. doi:10.1002/hed.26006

Kincaid, J. P., Fishburne Jr, R. P., Rogers, R. L., \& Chissom, B. S. (1975). Derivation of new readability formulas (automated readability index, fog count and flesch reading ease formula) for navy enlisted personnel. Defense Technical Information Center, U.S. Department of Defense Retrieved from http://stars.library.ucf.edu/cgi/viewcontent.cgi?article=1055\&context=istlibrary

Krantz, D. S., Baum, A., \& Wideman, M. V. (1980). Assessment of Preferences for SelfTreatment and Information in Health-Care. J Pers Soc Psychol, 39(5), 977-990. doi:10.1037/0022-3514.39.5.977

Landis, J. R., \& Koch, G. G. (1977). The measurement of observer agreement for categorical data. biometrics, 159-174. doi:10.2307/2529310

Lazarus, R. S., \& Folkman, S. (1984). Stress, appraisal, and coping. New York: Springer Pub. Co.

Lin, H. Y., Chen, S. C., Peng, H. L., \& Chen, M. K. (2015). Unmet information needs and clinical characteristics in patients with precancerous oral lesions. Eur J Cancer Care (Engl), 24(6), 911-919. doi:10.1111/ecc.12368

Lopez-Jornet, P., Camacho-Alonso, F., \& Sanchez-Siles, M. (2012). Patient information preferences and behaviour in relation to oral biopsies. Br J Oral Maxillofac Surg, 50(8), E115-E118. doi:10.1016/j.bjoms.2011.12.010

Luker, K. A., Beaver, K., Leinster, S. J., Owens, R. G., Degner, L. F., \& Sloan, J. A. (1995). The information needs of women newly diagnosed with breast cancer. $J$ Adv Nurs, 22, 134-141. doi:10.1046/j.1365-2648.1995.22010134.x 
Mastaglia, B., Toye, C., \& Kristjanson, L. J. (2003). Ensuring content validity in instrument development: challenges and innovative approaches. Contemp Nurse, 14(3), 281291. doi:10.5172/conu.14.3.281

Mehanna, H. M., Rattay, T., Smith, J., \& McConkey, C. C. (2009). Treatment and followup of oral dysplasia - a systematic review and meta-analysis. Head Neck., 31, 1600-1609. doi:10.1002/hed.21131

Mokkink, L. B., Prinsen, C. A. C., Patrick, D. L., Alonso, J., Bouter, L. M., de Vet, H. C. W., \& Terwee, C. B. (2019). COSMIN Study Design checklist for Patient-reported outcome measurement instruments. In. Amsterdam: Amsterdam University Medical Centers.

Moses, N., Wiggers, J., Nicholas, C., \& Cockburn, J. (2005). Prevalence and correlates of perceived unmet needs of people with systemic lupus erythematosus. Patient Educ Couns, 57(1), 30-38. doi:10.1016/j.pec.2004.03.015

Nankivell, P., Dunn, J., Langman, M., \& Mehanna, H. (2012). Feasibility of recruitment to an oral dysplasia trial in the United Kingdom. Head \& neck oncology, 4(1), 1-5. doi:10.1186/1758-3284-4-40

National Institute for Clinical Excellence. (2012). Patient experience in adult NHS services: improving the experience of care for people using adult NHS services: Clinical Guidelines (CG138). London: NICE Retrieved from https://www.nice.org.uk/guidance/cg138

Neumann, M., Wirtz, M., Ernstmann, N., Ommen, O., Längler, A., Edelhäuser, F., . . . Pfaff, H. (2011). Identifying and predicting subgroups of information needs among cancer patients: an initial study using latent class analysis. Support Care Cancer, 19(8), 1197-1209. doi:10.1007/s00520-010-0939-1

Pian, W., Song, S., \& Zhang, Y. (2019). Consumer health information needs: A systematic review of measures. Inf Process Manag, 102077. doi:10.1016/j.ipm.2019.102077

Porter, S., Gueiros, L. A., Leao, J. C., \& Fedele, S. (2018). Risk factors and etiopathogenesis of potentially premalignant oral epithelial lesions. Oral Surg Oral Med Oral Pathol Oral Radiol, 125(6), 603-611. doi:10.1016/j.0000.2018.03.008

Prinsen, C. A. C., Mokkink, L. B., Bouter, L. M., Alonso, J., Patrick, D. L., de Vet, H. C. W., \& Terwee, C. B. (2018). COSMIN guideline for systematic reviews of patient- 
reported outcome measures. Qual Life Res, 27(5), 1147-1157.

doi:10.1007/s11136-018-1798-3

Rask, M. (2017). Women receiving notification of an abnormal Pap smear result:experiences and impact on health-related quality of life. (Doctoral thesis, comprehensive summary). Linnaeus University, Faculty of Health and Life Sciences, Linnaeus University Press.

Rotter, J. B. (1966). Generalized expectancies for internal versus external control of reinforcement. Psychol Monogr, 80(1), 1-28. doi:10.1037/h0092976

Rutten, L. J., Arora, N. K., Bakos, A. D., Aziz, N., \& Rowland, J. (2005). Information needs and sources of information among cancer patients: a systematic review of research (1980-2003). Patient Educ Couns, 57(3), 250-261. doi:10.1016/j.pec.2004.06.006

Shepperd, J. A., Howell, J. L., \& Logan, H. (2014). A survey of barriers to screening for oral cancer among rural Black Americans. Psychooncology, 23(3), 276-282. doi:10.1002/pon.3415

Sim, J., \& Wright, C. C. (2005). The Kappa Statistic in Reliability Studies: Use, Interpretation, and Sample Size Requirements. Phys Ther, 85(3), 257-268. doi:10.1093/ptj/85.3.257

Syx, R. L. (2008). The practice of patient education: the theoretical perspective. Orthop Nurs, 27(1), 50-54; quiz 55-56. doi:10.1097/01.NOR.0000310614.31168.6b

Tadakamadla, J., Kumar, S., Lalloo, R., \& Johnson, N. W. (2017). Qualitative analysis of the impact of Oral Potentially Malignant Disorders on daily life activities. PLoS One, 12(4), e0175531. doi:10.1371/journal.pone.0175531

Tariman, J. D., Doorenbos, A., Schepp, K. G., Singhal, S., \& Berry, D. L. (2014). Information Needs Priorities in Patients Diagnosed With Cancer: A Systematic Review. J Adv Pract Oncol, 2014(5), 115-122. Retrieved from https://www.advancedpractitioner.com/issues/volume-5,-number-2-(marapr2014)/information-needs-priorities-in-patients-diagnosed-with-cancer-a-systematicreview.aspx

Terwee, C. B., Prinsen, C. A. C., Chiarotto, A., Westerman, M. J., Patrick, D. L., Alonso, J., . . Mokkink, L. B. (2018). COSMIN methodology for evaluating the content 
validity of patient-reported outcome measures: a Delphi study. Qual Life Res, 27(5), 1159-1170. doi:10.1007/s11136-018-1829-0

van der Waal, I. (2014). Oral potentially malignant disorders: Is malignant transformation predictable and preventable? Medicina oral, patologia oral y cirugia bucal, 19(4), e386-e390. doi:10.4317/medoral.20205

Waldron, N., Brown, S., Hewlett, S., Elliott, B., McHugh, N., \& McCabe, C. (2011). 'It's more scary not to know': a qualitative study exploring the information needs of patients with systemic lupus erythematosus at the time of diagnosis.

Musculoskeletal Care, 9(4), 228-238. doi:10.1002/msc.221

Weymann, N., Harter, M., \& Dirmaier, J. (2016). Information and decision support needs in patients with type 2 diabetes. Health Informatics J, 22(1), 46-59. doi: $10.1177 / 1460458214534090$

White, C., \& Gallagher, P. (2010). Effect of patient coping preferences on quality of life following renal transplantation. J Adv Nurs, 66(11), 2550-2559. doi:10.1111/j.13652648.2010.05410.x 
Figure 1 Visual representations of the experts' responses to the content assessment $(n=13)$.

Figure 2 Steps performed to identify and recruit potentially eligible patients. 
Table 1 Inclusion and exclusion criteria for the study.

Inclusion Criteria

1. Adults aged 18 or above at the time of the screening visit and subjective disclosure of good command of English language both written and spoken.

2. Being able to consent.

3. Diagnosed with OED as per current standard diagnostic criteria (EI-Naggar et al., 2017).

4. No concurrent malignancy in the head and neck or elsewhere.

\section{Exclusion Criteria}

1. Individuals under 18 years old.

2. Unable to speak and read English and to understand the diagnosis of OED.

3. Concurrent malignancy in the head and neck or elsewhere.

4. Clinical judgement (e.g. individuals diagnosed with a debilitating disorder which may affect the responses to ODIN-Q). 
Table 2 Examples of the feedback from experts and patients and performed actions for ODIN-Q (version 1.0)

Criteria Comment/s Action taken

\begin{tabular}{|c|c|c|}
\hline Clarity & \multicolumn{2}{|c|}{ Oral Medicine experts } \\
\hline & $\begin{array}{l}\text { Some grammatical errors in many of the questions making } \\
\text { the questions less clear but if these are addressed will be } \\
\text { easier for patients to understand and answers (expert 06) }\end{array}$ & $\begin{array}{l}\text { The items were revised grammatically by the core study } \\
\text { team (AA, RNR and SRP) }\end{array}$ \\
\hline & $\begin{array}{l}\text { "Clinical features" is an expression that probably means } \\
\text { nothing for someone without medical background (expert } \\
\text { 08) }\end{array}$ & $\begin{array}{l}\text { The question 'what are the clinical features of OED?' } \\
\text { was replaced by 'how it looks inside the mouth?' }\end{array}$ \\
\hline & $\begin{array}{l}\text { Some questions contain jargon which may not be } \\
\text { understood by patients... (e.g. clinical features) (expert } \\
\text { 12) }\end{array}$ & \\
\hline
\end{tabular}

This article is protected by copyright. All rights reserved 
'How the OED acts in the body?' I think that this is an odd This item was replaced by 'what is likely to happen to question, and I am not sure if my patients would OED in the future' and moved to the end of 'information understand this. Also, I would not put this as the first about the disease' domain (Q10) question (expert 10)

\begin{tabular}{|c|c|c|}
\hline Statement fit & $\begin{array}{l}\text { My suggestion is to test the questionnaire with a group of } \\
\text { people with demographic characteristics similar to the } \\
\text { group you expect to survey, but without any medical } \\
\text { background (expert 08) }\end{array}$ & The ODIN-Q was subsequently reviewed by five patients \\
\hline \multirow[t]{3}{*}{ Redundancy } & $\begin{array}{l}\text { I wonder if all patients will feel able to complete because } \\
\text { of there being so many to answer (expert 06) }\end{array}$ & Twenty-one unnecessary items were eliminated \\
\hline & This is a huge number of questions (expert 11) & \\
\hline & \multicolumn{2}{|c|}{ Patients } \\
\hline & Wording is weird in the "why and why not the OED is & The item was changed to 'what will happen if it is not \\
\hline
\end{tabular}

This article is protected by copyright. All rights reserved 


\begin{tabular}{|c|c|c|}
\hline & being treated?" & treated?' \\
\hline \multirow[t]{4}{*}{ Relevance } & $\begin{array}{l}\text { Not applicable for job and career please as some of us are } \\
\text { retired }\end{array}$ & $\begin{array}{l}\text { The following was added to the question; 'N.B. If you are } \\
\text { no longer working, please skip to question 28' }\end{array}$ \\
\hline & $\begin{array}{l}\text { I don't have health insurance - will that make me ineligible } \\
\text { for treatment? }\end{array}$ & $\begin{array}{l}\text { The question about health insurance as the validation } \\
\text { study was conducted in the NHS hospitals }\end{array}$ \\
\hline & $\begin{array}{l}\text { Not much point in getting information about screening } \\
\text { when I have it already }\end{array}$ & $\begin{array}{l}\text { None as ODIN-Q was aimed for use despite the stage of } \\
\text { the disease and treatment }\end{array}$ \\
\hline & $\begin{array}{l}\text { The treatments I was offered were cut it out or watch...so I } \\
\text { don't know how "when and how to know the treatment is } \\
\text { working"' are relevant to me }\end{array}$ & \\
\hline \multirow[t]{2}{*}{ Acceptability } & This is too long & $\begin{array}{l}\text { Further two items were removed, and others underwent } \\
\text { further reduction of words and syllables to improve } \\
\text { readability }\end{array}$ \\
\hline & $\begin{array}{l}\text { Don't think it is acceptable to discuss spiritual and } \\
\text { religious things with the doctor }\end{array}$ & The item about spiritual/religious support was omitted \\
\hline
\end{tabular}

This article is protected by copyright. All rights reserved 
Table 3 Internal consistency (Cronbach's $\alpha$ ) of domains and subscales of ODIN-Q.

ODIN-Q Domain Number $\quad$ Cronbach's coefficient

of Amount of information Degree of importance

items received subscale subscale

\begin{tabular}{llll}
\hline Information about the & 10 & .74 & .84
\end{tabular}

disease

Investigative tests

3

$.54(.62)^{a}$

$.69(.81)^{\mathrm{a}}$

Treatments

$6 \quad .84$

.85

Physical aspects

4

.75

.84

Psychosocial aspects

4

$4 \quad .60(.79)^{\mathrm{b}}$

$.58(.75)^{b}$

Medical system and

8

.78

.83

access to information

\begin{tabular}{llll}
\hline All domains combined & 35 & $.92(.93)^{\mathrm{c}}$ & $.94(.95)^{\mathrm{c}}$
\end{tabular}

a After eliminating item 12 'the genetic testing and chance of inheritance to children' from the analysis.

${ }^{\mathrm{b}}$ After eliminating item 27 'how the disease/treatment may affect my job/career?' from the analysis.

c The Cronbach's $\alpha$ scores after omitting item 12 and 27 from the analyses. 
Table 4 Reliability coefficients (test-retest) of the ODIN-Q.

\section{ODIN-Q item}

\section{Weighted Kappa's}

coefficient (K)

$\begin{array}{cc}\begin{array}{c}\text { Amount of } \\ \text { information }\end{array} & \begin{array}{c}\text { Degree of } \\ \text { importance }\end{array} \\ \text { received } & \text { subscale } \\ \text { subscale } & \end{array}$

Information about the disease

\begin{tabular}{lll} 
What OED is? & 0.64 & 0.53 \\
\hline How common is it? & 0.50 & 0.38 \\
\hline Risk factors & 0.39 & 0.29 \\
\hline How it looks in the mouth or lips? & 0.28 & 0.48 \\
\hline Whether it is contagious or not? & 0.69 & 0.63 \\
\hline The role of human papilloma virus. & 0.46 & 0.49
\end{tabular}



Disease grades and risk of developing mouth
0.56
0.48

cancer.

What will happen if continues to smoke or drink

$0.56 \quad 0.59$ alcohol?

What is a safe level of alcohol to drink?

0.35

0.41

What is likely to happen to OED in the future?

0.57

0.59

Investigative tests

The screening and early detection.

0.44

0.33

The genetic testing and chance of inheritance

$0.29 \quad 0.45$

to children.

Benefits, risks, how each test works, and the

0.62

0.44 meaning of test results.

\section{Treatments}

$\begin{array}{lll}\text { What will happen if it is not treated? } & 0.42 & 0.61\end{array}$

$\begin{array}{lll}\text { Treatment options, benefits, risks, and how } & 0.55 & 0.52\end{array}$ each treatment works.

$\begin{array}{lll}\text { How the disease/treatment affects the quality } & 0.55 & 0.42\end{array}$ of life.

\begin{tabular}{lll} 
Self-management at home. & 0.65 & 0.46 \\
\hline Complementary and alternative medicine. & 0.51 & 0.54 \\
Chances of a cure. & 0.60 & 0.54
\end{tabular}

\section{Physical aspects}

\begin{tabular}{lll} 
How frequent and severe are the symptoms? & 0.40 & 0.40 \\
\hline $\begin{array}{l}\text { Chances of spreading to an adjacent or distant } \\
\text { body part. }\end{array}$ & 0.43 & 0.48 \\
$\begin{array}{l}\text { How the disease/treatment affects daily } \\
\text { physical activities. }\end{array}$ & 0.63 & 0.39 \\
\hline Diet and nutrition. & 0.62 & 0.64
\end{tabular}

\section{Psychosocial aspects}




\begin{tabular}{lll} 
Fear of progression to cancer. & 0.66 & 0.20 \\
\hline $\begin{array}{l}\text { Coping with the possible effects of the } \\
\text { disease/treatment. }\end{array}$ & 0.65 & 0.42 \\
\hline How the disease/treatment affects social life. & 0.60 & 0.51 \\
\hline How the disease/treatment affects job/career. & 0.50 & 0.59 \\
\multicolumn{1}{c}{ Medical system and access to information } & \\
\hline $\begin{array}{l}\text { The experience of the doctor and other health } \\
\text { care staff. }\end{array}$ & 0.33 & 0.54 \\
\hline Seeking another professional opinion. & 0.41 & 0.43 \\
\hline Physical support and advice. & 0.47 & 0.55 \\
\hline Psychological support and advice. & 0.54 & 0.44 \\
\hline Community/patient support groups. & 0.49 & 0.53 \\
\hline Health promotion (e.g. promoting one's health & 0.73 & 0.57 \\
\hline \begin{tabular}{l} 
literacy). \\
\hline The lifestyle adjustment
\end{tabular} & 0.62 & 0.58 \\
\hline Research and recruitment for clinical trials. & 0.76 & 0.54 \\
\hline
\end{tabular}


Table 5 The spearman's correlation coefficients between ODIN-Q and KHOS.

\begin{tabular}{lccccc}
\hline & $\begin{array}{c}\text { Amount of } \\
\text { information } \\
\text { received }\end{array}$ & $\begin{array}{c}\text { Degree of } \\
\text { importance }\end{array}$ & $\begin{array}{c}\text { KHOS } \\
- \text { I }\end{array}$ & $\begin{array}{c}\text { KHOS- } \\
\text { B }\end{array}$ & $\begin{array}{c}\text { Total } \\
\text { KHOS } \\
\text { score }\end{array}$ \\
\hline $\begin{array}{l}\text { Amount of } \\
\text { information } \\
\text { received }\end{array}$ & 1 & .102 & $.232^{*}$ & -.047 & .108 \\
\hline $\begin{array}{l}\text { Degree of } \\
\text { importance }\end{array}$ & .102 & 1 & -.114 & -.042 & -.084 \\
\hline KHOS-I & $.232^{*}$ & -.114 & 1 & $.355^{* *}$ & $.811^{* *}$ \\
\hline KHOS-B & -.047 & -.084 & $.355^{* *}$ & 1 & $.816^{* *}$ \\
\hline Total KHOS & .108 & -.084 & $.811^{* *}$ & $.816^{* *}$ & 1 \\
score & & & & & \\
\hline
\end{tabular}

${ }^{*}$ Correlation is significant at the 0.05 level (2-tailed).

${ }^{*}$ Correlation is significant at the 0.01 level (2-tailed). 
Does it seem to be asking about the same general topic?

Are any of the items redundant/ repetitive?

Do the items match the topic? Is the questionnaire clear?

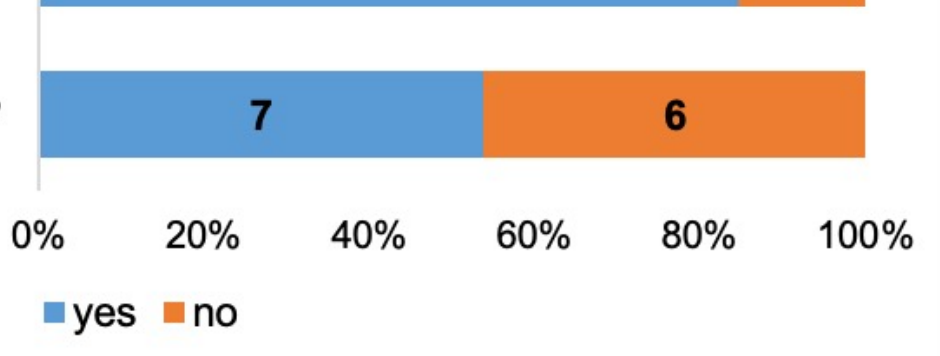

odi_13726_f1.tiff

11

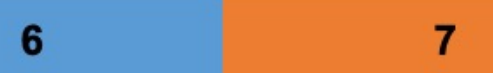

11

2

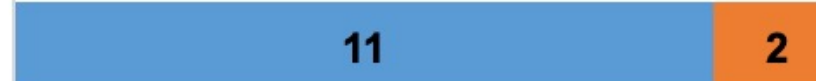


A consecutive sample of 135 patients, who met the study inclusion criteria and none of the exclusion criteria, were invited to the participate after their routine clinical visit

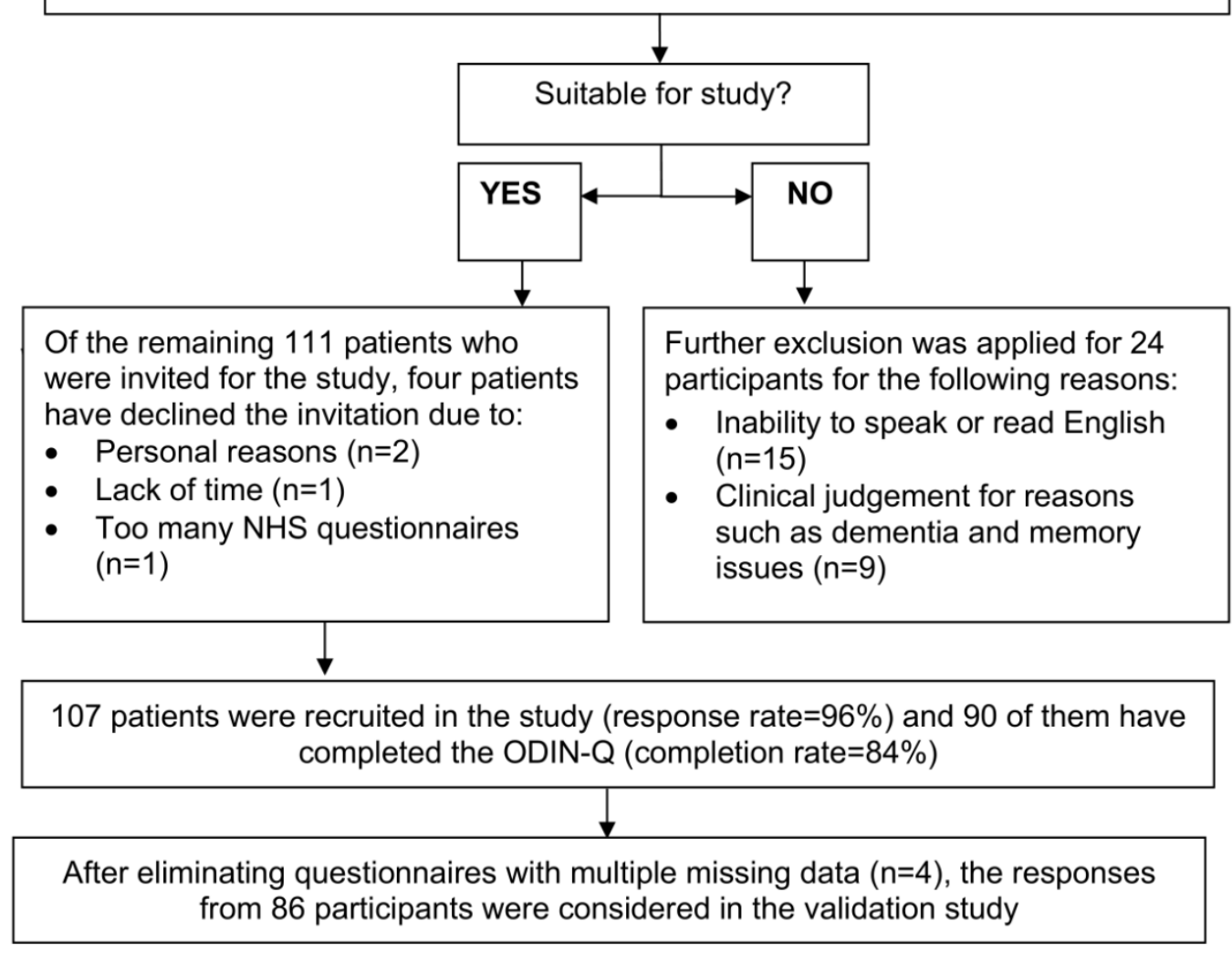

odi_13726_f2.tiff

This article is protected by copyright. All rights reserved 